\title{
Spontaneous Splenic Rupture due to Dengue Fever: Report of Two Cases
}

\author{
Maria Roberta Meneguetti Seravali, Antônio Henrique Gomes dos Santos, Carlos Eduardo Fávero Costa, Diego Teixeira Alves \\ Rangel, Leonardo Fernandes Valentim and Raphael Moreira Gonçalves \\ Jacarepaguá Hospital; Rio de Janeiro, RJ, Brazil
}

\begin{abstract}
Dengue is a febrile illness caused by Flavivírus and mainly transmitted by the mosquito Aedes aegypiti which have been a serious epidemic in Rio de Janeiro. In most of cases it was a self limited disease. We report two cases of a serious and rare complication of this viral infection.
\end{abstract}

Key-Words:

Approximately 50-100 millions peoples are infected by dengue virus per year in more than 100 countries. In Brazil around 3 millions peoples contracted these illness since 1986, 43.523 cases are notified since a quarter of this year in Rio de Janeiro's state (36\% of total cases in Brazil).Generally, this infection is asymptomatic or a feverish acute illness. In a few cases dengue fever can progress to life-threatening dengue hemorrhagic fever and dengue shock syndrome. The spleen rupture is a rare complication for this illness and can be misdiagnosed due to misinterpretation of the shock syndrome of dengue fever. We report two cases of spontaneous splenic rupture with favorable evolution after splenectomy in patients with hemorrhagic dengue fever in Jacarepaguá Hospital during the three first month of this year.

\section{Case Reports \\ Case 1}

JCMS, 27 year old man, living in Rio de Janeiro, sought the emergency room in January, 2008, due to a generalized myalgias, abdominal pain, pallid skin and mucosa, filiform pulses, low arterial blood pressure, globus abdomen with defense. There were no abdominal trauma antecedents. Diagnostic peritoneal lavage was positive for blood. An exploratory laparotomy revealed massive hemoperitoneum (approximately 3 liters), spleen grossly congested with rupture of middle third and perisplenic hematoma. Splenectomy was performed. Anatomo-pathological examination showed a spleen weighing $489 \mathrm{~g}$ and measuring $18 \times 13 \times 8 \mathrm{~cm}$ with a gross capsule, a $8 \mathrm{~cm}$ hematoma, hyperplasia follicular, sinusoids congest with hemorrhagic focus. There was no evidence of malignancy or granulomas. Dengue fever serology (ELISA, with IgM and IgG search) was positive in two serums samples. Serology (ELISA, with IgM search) of Epstein Barr, mononucleosis, toxoplasmosis, hepatitis and cytomegalovirus was negative. The patient has gone home thirty days after the surgery with completely recovery.

Received on 15 September 2008; revised 20 November 2008. Address for correspondence: Dr. Maria Roberta Meneguetti Seravali Machado de Assis, 39 apto-201 Flamengo, Rio de Janeiro - RJ, Brazil. Zip code: 22220-060. E-mail: betameneguetti@yahoo.com.br.

The Brazilian Journal of Infectious Diseases 2008;12(6):538-540. (C) 2008 by The Brazilian Journal of Infectious Diseases and Contexto Publishing. All rights reserved.
Case 2

TSJ, 20 year old man, living in Rio de Janeiro, was admitted in the emergency room in March, 2008, due to feverish acute illness, headache, generalized myalgias, abdominal pain in right hypochondrium irradiated to left flank and diarrhea with six days of evolution. Laboratory tests demonstrated normal hematocrit and hemoglobin, thrombocytopenia $(46,800)$, leucocytes increase $(45,300)$, normal amylase, increased serum activity of AST (3964 U/L) and ALT (1,240 U/L), creatinine (1.9) and bilirubin total (3.13). There was no history of travel for endemic areas for leptospirosis, infect illness or use of drug. The initial suspects were: acute hepatitis, feverish syndrome, sepsis, leptospirosis and dengue. Ultrasonography showed a diffused, heterogenic and increased spleen (approximately $15 \mathrm{~cm}$ ) with moderate ascites. The computed tomography evidenced: pleural bilateral effusion, ascites, hepatic and splenic congestion, a subcapsular spleen hematoma without any alterations (Figure 1). The patient received a conservative treatment. On the fourth day of illness, he was admitted in ICU with pallid skin and mucosa, filiform pulses, low arterial blood pressure and severe abdominal pain. Two units of pack red blood cells and antibiotics were given. A new computed tomography evidenced pleural bilateral effusion, moderate ascites, hemorrhagic focus in liver and renal cortical, a large subcapsular hematoma with congested and increase spleen (Figures 2 and 3). An exploratory laparotomy revealed hemoperitoneum, grossly congested spleen with a big subcapsular hematoma. Splenectomy was performed (Figure 4). Anatomo-pathological examination showed a spleen weighing $785 \mathrm{~g}$ and measuring $16,5 \times 9,5 \times 8 \mathrm{~cm}$ with a gross and granulose capsule, a $7 \times 6 \mathrm{~cm}$ hematoma, sinusoids congested with multiple hemorrhagic foci, hemosiderin deposit, acute and chronic inflammatory process with extensive necroses areas. Dengue fever serology (ELISA, with IgM and IgG search) was positive in two serums samples. Serology (ELISA, with IgM search) of B hepatitis was negative. The patient has gone home sixteen days after de surgery without complications.

\section{Discussion}

Currently, dengue is the most significant mosquito-borne viral disease that affects humans [1]. Approximately 50-100 millions peoples are infected per year in more than 100 countries [2]. The virus belongs to the genus Flavivirus of 
Figure 1. Computed tomography (Patient 2, second day of illness): ascites, hepatic and splenic congestion and a subcapsular spleen hematoma.

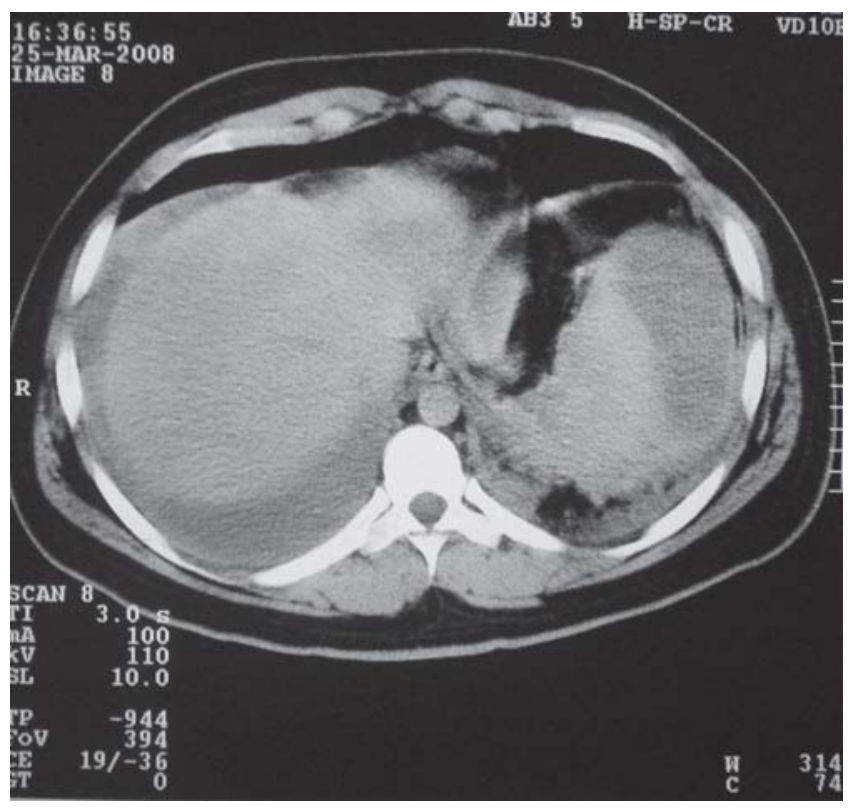

Figure 3. Computed tomography (Patient 2, fourth day of illness): hemorrhagic focus in renal cortical.

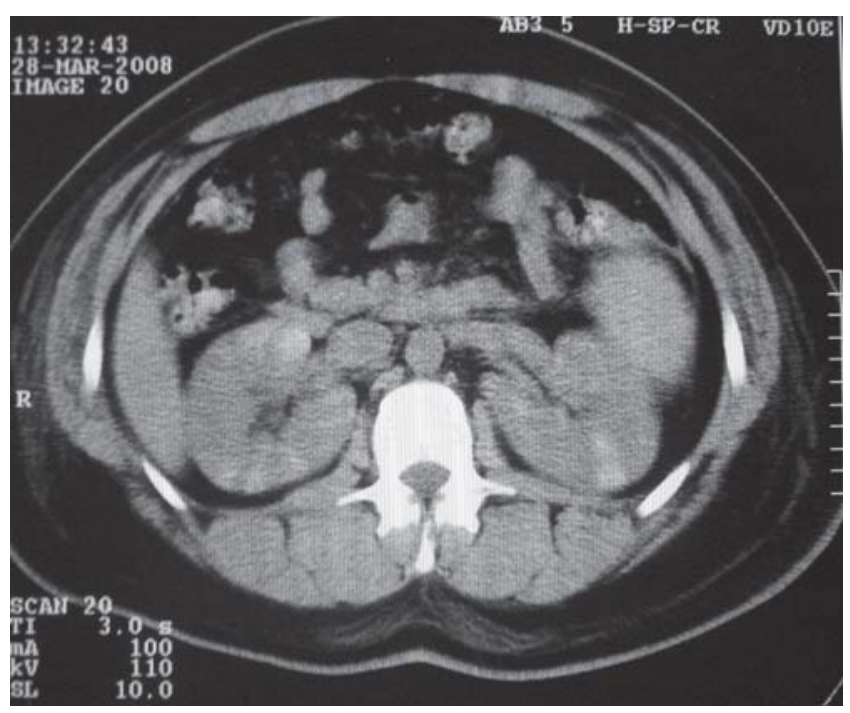

the family Flaviviridae (group B arbovirus). Aedes aegypti is the major vector and the true reservoir for the virus [3]. The infection occurs typically in the warmest months without qualitative differences for the Brazilian geographic regions. However, this disease has an important quantitative difference. It was been observed two clusters in the country regarding the number of case notifications. The first cluster is formed by the North-East and South-East regions, that sum about
Figure 2. Computed tomography (Patient 2, fourth day of illness): moderate ascites, hemorrhagic focus in liver, a large subcapsular hematoma with congested and increase spleen.

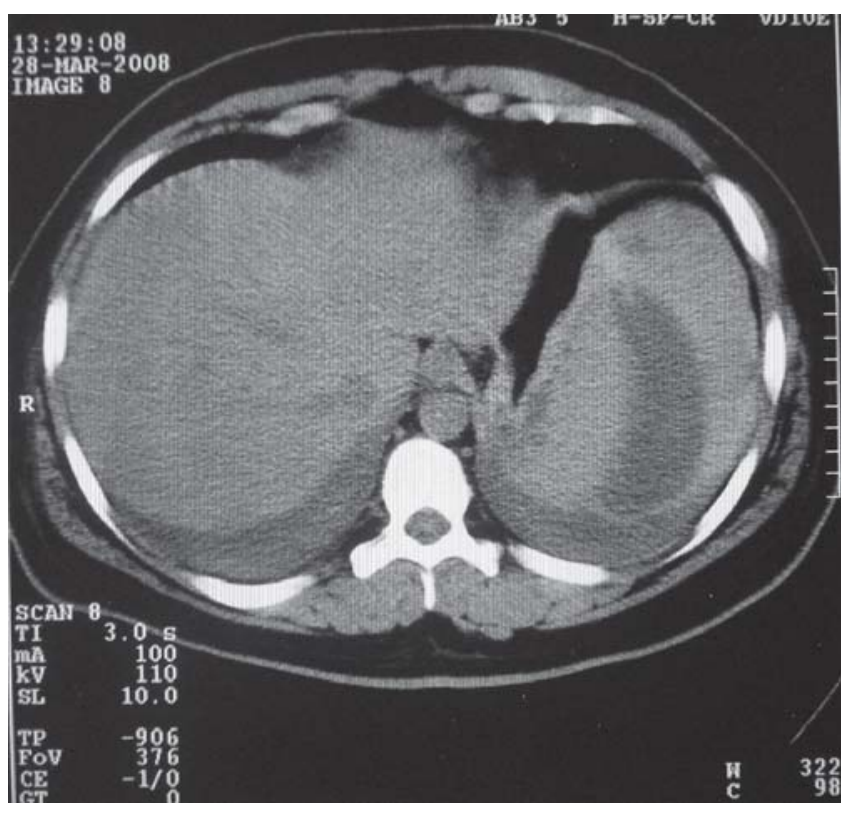

Figure 4. Macroscopic (Patient 2): Grossly congested spleen with a big subcapsular hematoma.

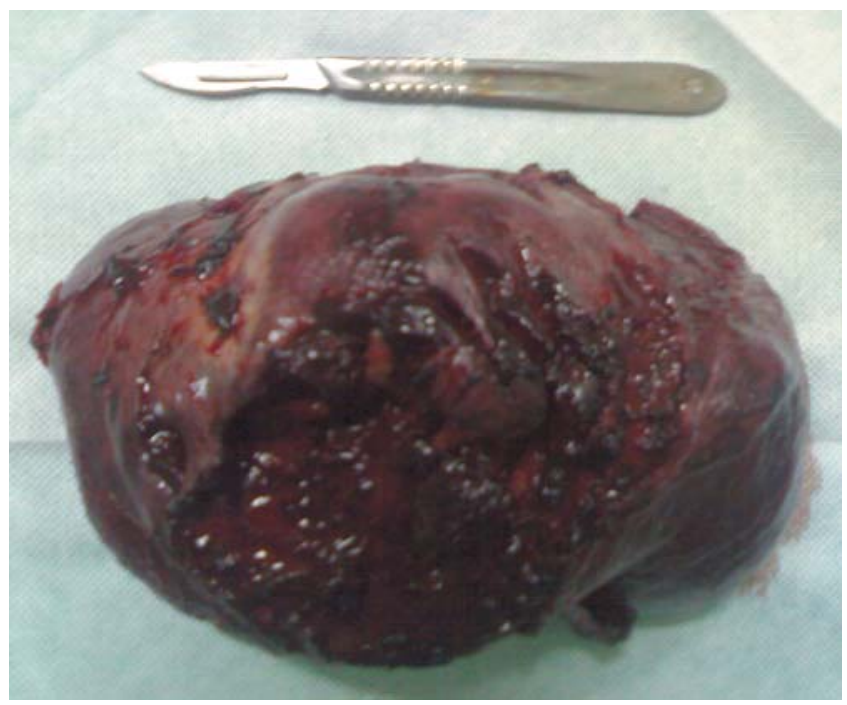

$86 \%$ of the all notifications; and the second is formed by the South, North and Center-West regions [4]. For most persons this infection is asymptomatic or a feverish acute illness. In a few cases dengue fever can progress to life-threatening dengue hemorrhagic fever and dengue shock syndrome, the characteristic feature of which is increase capillary permeability [5], perivascular edema, without destruction of the vascular endothelium, liver parenchyma necrosis and lymph node, and 
thymus cell hyperplasia of the spleen [6]. The pathogenesis of dengue hemorrhagic fever is not well understood. Furthermore, direct injury by dengue virus to various vital organs such as skin, lungs, heart muscle, bone marrow, lymph nodes and liver has been documented [7]. The spleen, which is frequently congestive, bears subcapsular hematoma in $15 \%$ of cases [6]. Hemorrhages were also present in serous cavities [8]. An important increase in dengue hemorrhagic fever incidence accompanied the introduction of DEN-3, changing the overall clinical expression of the disease during the fourth epidemic. Failure to reach an early diagnosis and adequate treatment accounted for rather high dengue hemorrhagic fever case-fatality in Brazil, generally greater than 5.5\% [9]. The spleen rupture can be misdiagnosed due to misinterpretation of the shock syndrome of dengue fever [10]. Although it is a rare condition, it can be a fatal complication in the case of a non-quick and correct diagnostic. Conservative management has been used successfully for traumatic rupture of the spleen and several teams have reported good results in patients with infectious mononucleosis [11]. The therapy of spleen rupture caused by dengue fever depends of the patient's hemodinamic status. In cases of transfusion larger than two red blood cells or clinical aggravation, the splenectomy is imposing [12]. In these two cases reports, splenectomy was been performed and curative.

\section{References}

1. Figueiredo L.B., Cecílio A.C., Ferreira G.P., et al. Dengue virus 3 genotype 1 associated with dengue fever and dengue hemorrhagic fever, Brazil. Emerging Infectious Diseases 2008;14(2):314-6.
2. Ministério da Saúde. Vigilância Epidemiológica-Programa Nacional de Controle da Dengue no Brasil. Brasília, 2002. Available from h t t p : / / portal.saude.gov.br/portal/saude/ visualizar_texto.cfm?idtxt $=21389$.

3. Lupi O, Carneiro C.G., Coelho I.C.B. Mucocutaneous manifestations of dengue. An Bras Dermatol 2007;82(4):291-305.

4. Câmara F.P., Theophilo R.L.G., Santos G.T, et al. Regional and dynamics characteristics of dengue in Brazil: a retrospective study. Rev Soc Bras Med Trop 2007;40(2):192-6.

5. Gubler D.J. Dengue and Dengue Hemorragic Fever. Clin Microbiol Rev 1998;11(3):480-96.

6. Bhamarapravati N., Tuchinda P., Boonyapaknavik V. Pathology of Thailand haemorrhagic fever. A study of 100 autopsy cases. Ann Trop Med Parasitol 1967;61:500-10.

7. Srichaikul T., Punyagupta S., Kanchanapoom T., et al. Hemophagocytic syndrome in Dengue hemorrhagic fever with severe multiorgan complications. J Med Assoc Thai 2008;91(1):104-9.

8. Basílio de Oliveira C.A., Aguiar G.R., Balzana M.S., et al. Pathologic study of a fatal case of dengue-3 virus infection in Rio de Janeiro, Brazil. The Brazilian Journal of Infections Diseases 2005;9(3):341-7.

9. Teixeira M.G., Costa M.C.N, Barreto M.L., Mota E. Dengue and dengue hemorrhagic fever epidemics in Brazil: what research is needed based on trends, surveillance, and control experiences? Caderno de Saúde Pública 2005;21(5):1307-15.

10. Miranda L.E.C., Miranda S.J.C., Rolland M. Case report: spontaneous rupture of the spleen due to dengue fever. The Brazilian Journal of Infections Diseases 2003; $7(6): 423-5$.

11. Imbert P., Sordet D., Hovette P., Touze J.E. Spleen rupture in a patient with dengue fever. Trop Med Parasitol 1993;44:327-8.

12. Rapp C., Debord T., Imbert P., Lambotte O., Roué R. Splenic rupture in infectious disease: splenectomy or conservative treatment? Report of three cases. Rev Méd Interne 2002;23(1):85-91. 